\title{
Article \\ Explanatory or Dispositional Optimism: Which Trait Predicts Eco-Friendly Tourist Behavior?
}

\author{
Farrukh Rafiq ${ }^{1}{ }^{(\mathbb{C}}$, Syed Khusro Chishty ${ }^{1}$ and Mohd Adil ${ }^{2, *(\mathbb{D})}$ \\ 1 Department of Business Administration, College of Administrative and Financial Sciences, Saudi Electronic \\ University, Jeddah 23442, Saudi Arabia; f.ahmad@seu.edu.sa (F.R.); s.chishty@seu.edu.sa (S.K.C.) \\ 2 Department of Management Studies, NIT Hamirpur, Hamirpur 177005, India \\ * Correspondence: adil.dms@nith.ac.in
}

check for updates

Citation: Rafiq, F.; Chishty, S.K.; Adil, M. Explanatory or Dispositional Optimism: Which Trait Predicts Eco-Friendly Tourist Behavior? Sustainability 2022, 14, 2994. https:// doi.org/10.3390/su14052994

Academic Editors: Azilah Kasim and Alan Fyall

Received: 23 January 2022

Accepted: 28 February 2022

Published: 4 March 2022

Publisher's Note: MDPI stays neutral with regard to jurisdictional claims in published maps and institutional affiliations.

Copyright: (C) 2022 by the authors. Licensee MDPI, Basel, Switzerland. This article is an open access article distributed under the terms and conditions of the Creative Commons Attribution (CC BY) license (https:// creativecommons.org/licenses/by/ $4.0 /)$.

\begin{abstract}
Recently, researchers have been drawn to the literature surrounding positive psychology. The role of explanatory and dispositional optimism in eco-friendly tourism has been largely ignored by researchers, even though positive psychology, or optimism, has been studied in the sustainability domain. The purpose of this study is to determine which trait predicts eco-friendly tourist behavior. In the study, the data were collected online using Amazon Mechanical Turk from 400 respondents, and the model was assessed using partial least squares structural equation modeling. Findings revealed that in terms of predicting eco-friendly tourism behavior, dispositional optimism outperformed explanatory optimism. Furthermore, this study found that environmental concern positively moderates the association between optimism (dispositional and explanatory) and eco-friendly tourism behavior. This study has wide-ranging implications for tourism managers, practitioners, and academics.
\end{abstract}

Keywords: dispositional optimism; explanatory optimism; eco-friendly tourist behavior; positive psychology; green consumer behavior

\section{Introduction}

According to the United Nations World Tourism Organization [1], approximately one billion tourists travel abroad each year, contributing $10 \%$ and $6 \%$ to global GDP and total exports, respectively. Despite being a leader in the service sector, tourism generates a large amount of greenhouse gases [2]. As a result, the tourism industry is among the most unsustainably affected industries. Hence, studying eco-friendly behavior within the ambit of tourism is critical as this industry exhibits negative spillover effect over the environment, the society, and the economy.

Environmental degradation has resulted in the development of the "sustainable development concept" that encourages individuals to practice eco-friendly behavior in order to conserve the environment [3]. A large number of visitors expressed their willingness to behave ethically when they are at home or on vacation [4,5]. Paradoxically, a reduction in ethical behavior among tourists at the destination has been documented in the extant literature [6-8]. It is possible to attribute the lack of consensus in the literature to individual and situational factors that can influence individuals' ethical behavior, for instance-personal values, attitude, perceived behavioral control, social norms, personality traits, knowledge, moral obligations, and infrastructure availability [9-14]. In fact, studies in the area of tourism consumption accentuated environmental behavior, specifically performed by eco-tourists [15].

In an attempt to identify more stable factors, previous researchers have linked life satisfaction or subjective cognition to personality traits $[7,15]$. While, there has been an escalating interest in positive aspects of human behavior and personality [15,16], optimism has become the focus of a lot of research and theory in recent years [17,18]. Despite this, little is known about the influence of optimism on an individual's behavior in social 
situations [19]. The two main scientific conceptions of optimism are dispositional optimism and explanatory optimism [19-22]. Sadiq [19] argued that even though there is a lack of empirical research to support whether dispositional optimism and explanatory optimism are conceptually related or not, previous researchers [2,5] agree that the concurrent effect of dispositional and explanatory optimism on individual's attitude and behavior is not well-studied empirically. As we know, people with different personality traits behave differently toward the safety of the environment [16-18], and scholars such as Kaida and Kaida [18] and Sadiq [19] have recommended examining two types of optimism, namely dispositional and explanatory optimism in relation to ethical behavior. Hence, this research aims to determine which type of optimism best predicts tourists' eco-friendly behavior.

Additionally, prior scholars such as Amatulli, Angelis, and Stoppani [23] and Kim, Kim, Han, and Holland [24] suggested that environmental concern is an important factor in driving tourists' eco-friendly decision-making process. Meanwhile scholars such as Verma, Chandra, and Kumar [25] have emphasized the importance of examining the role of environmental concerns in tourism. We further noted that the use of environmental concern as a moderator between personality traits and tourists' actual behavior may lend a newer dimension and essentially reduce the much debated attitude-behavior gap, which surprisingly has not yet been considered in tourism domain. Therefore, this study responds to the call by examining the role of environmental concern as a moderator between personality traits and actual behavior.

In terms of environmental consciousness, Indians are among the most conscientious [20] and environment concerned [22]. Additionally, the hospitality and tourism industry contributed approximately 6.5\% to the total GDP of India in 2019 [21]; thus, it stimulates the growth of its economy. In this backdrop, this research contributes to the developing nation by focusing on India and Indian tourists.

Based on this, the current study proposes two research questions: (RQ1) Do personality traits (dispositional and explanatory optimism) influence tourists to display eco-friendly behavior? (RQ2) Does environmental concern actually moderates tourists' personality traits and eco-friendly behavior link? To address these research questions, this study aims to fill the gap in the literature in the following ways: First, based on the primary data, this study investigates the relationship between dispositional optimism, explanatory optimism, and eco-friendly tourist behavior. Second, to assess the relationship between tourists personality traits and their eco-friendly behavior, we examined the moderating effect of environmental concern. Therefore, the primary objective of this research is to examine the influence of dispositional and explanatory optimism on tourists' eco-friendly behavior and also assess the moderating role of environmental concern on the link tourists' personality traits-eco-friendly behavior in the context of India.

Following the introduction section, the rest of the article is structured as follows: Section 2 discusses recent literature around optimism and its two school of thoughts, research hypotheses and conceptualization of the research model. Section 3 presents the development of the survey instrument, the determination of sample size, and data collection. Section 4 covers preliminary analysis, hypotheses testing and results. Section 5 presents discussions and implications, followed by limitations and future research directions.

\section{Materials}

\subsection{Two Schools of Thought of Optimism}

Researchers and social scientists have advanced two different schools of thought. The first school of thought proposes optimism as an explanatory concept [26]; the second proposes "generalized outcome expectations" [27].

This first school of thought is founded on the learned helplessness theory (LHT), which has its roots in Maier's and Seligman's seminal works [28]. According to this theory, the uncontrollability of events leads to a low motivation level, a low level of cognition, and a low level of emotion. Therefore, if an individual fails to control the event, he/she loses motivation, loses the ability to judge the outcome, and becomes emotionally disturbed. 
Seligman, Abramson, Semmel, and Von Baeyer [29] used a reformulated LHT to define the attribution on the basis of past positive and negative events. Furthermore, on the basis of reformulated LHT, Peterson and Seligman [26] showed that future expectancies can be derived from a past bad event explanation. The above cited studies of Peterson and Seligman [26] and Seligman et al. [29] indicate that an individual's future expectancies of the outcome, i.e., optimism, depend heavily upon past negative experiences.

Peterson and Seligman [26] used the causal explanation method to determine future expectancies based on the given attributions - "internal vs. external, stable vs. unstable, and global vs. specific" (p. 348). In other words, an individual with an optimistic explanatory style uses unstable (low stability), external (low internality), and specific (low globality) factors to explain mishappenings, while on the other hand, an individual with a pessimistic explanatory style uses stable (low instability), global (low specificity), and internal (low externality) factors to explain past failures.

Founded in the seminal work of Carver and Scheier [30], the second school of thought is based on the control theory. This theory posits that individuals have a tendency to reduce "the comparison value that arises, due to the difference in his/her perception and reference value, which in turn, leads to the behavior" ([22], p. 2). According to the control theory [27], consumer actions influence the environment, resulting in a certain perception. After they develop perceptions, consumers close the loops, resulting in the so-called "negative feedback loop" ([31], p. 946).

According to the second school, optimism is a general outcome expectation. For instance, in Scheier and Carver ([27], p. 220), optimism was considered as "outcome expectancies based on the closed loop negative feedback system". As a result, self-focused consumers determine the existing conditions and predict the future. Following this, consumers tend to compare both existing and future conditions, which can result in discrepancies. When consumers attempt to reduce "these discrepancies", they may succeed or fail to do so. As a result, consumers who successfully reduce their discrepancies are referred to as optimistic, whereas those who fail to reduce their discrepancies are referred to as pessimistic.

Although both approaches, explanatory and generalized expectation, show similar results, they are not identical. There is a difference between how these two distinct schools of thought view future expectations. When we use the explanatory style, we apply the criteria of external, unstable, and specificity to explain what bad events happened in the past, whereas generalized outcome expectancy emphasizes what will happen in the future. This is in line with the observations of Tomakowsky, Lumely, Markowitz, and Frank [32] and Zhang et al. [33].

\subsection{Eco-Friendly Tourist Behavior}

Based on the literature, tourists' eco-friendly behavior is primarily determined by their concern for others and the environment. For example, Sadiq et al. [8] posited that tourists' eco-friendly behavior could be reflected through pro-environmental behavior, i.e., preferring eco-friendly hotels to "conventional ones". Gossling et al. [34] found that tourists in Tanzania are unaware of the impacts of their actions on the natural environment. In fact, higher humidity, more rain, and storms negatively influenced their travel decisions. In a similar study, Shamdub and Lebel [35] found that eco-friendly behavior of tourists in Thailand usually depends on a number of factors, such as the demographic background of the tourist, income level, traveling individually or in a group, duration of their stay, etc. Similar observations were also made by Eslaminosratabadi [36] where researchers observed that the level of intention to pay more for green hotels differs significantly across tourists' educational level, monthly income, and age. 


\subsection{Hypotheses and Model Development}

\subsubsection{Optimism and Eco-Friendly Tourist Behavior}

Eco-friendly tourist behavior is referred to as "an individual's aim to minimize his/her detrimental impacts on the natural environment and otherwise contribute to environmental protection" ([37], p. 111). Existing literature found dispositional optimism to be a motivator to engage in pro-environmental behavior (see [20,21]). Dispositional optimism encourages individuals to take risk $[38,39]$ and is also considered as one of the best coping strategies [40]. Pro-environmental behavior requires financial risk [41]; therefore-, we may interpret that tourist high on dispositional optimism is more likely to display eco-friendly behavior.

Likewise, explanatory optimism predicts pro-environmental behavior based on individuals' past experiences. Although we could not find a single study focusing on examining the role of explanatory optimism in motivating consumers to adopt pro-environmental behavior/pro-social behavior/eco-friendly behavior, it may be interpreted from the study of Tomakowsky et al. [32] and Zhang et al. [33] that explanatory optimism and dispositional optimism exhibit almost similar results. Thus, we hypothesized the following.

Hypothesis 1 (H1). Dispositional optimism positively influences eco-friendly tourist behavior.

Hypothesis 2 (H2). Explanatory style optimism positively influences eco-friendly tourist behavior.

\subsubsection{Moderating Effect of Environmental Concern}

Environmental concern refers to "the degree to which people are aware of problems regarding the environment and support efforts to solve them or indicate the willingness to contribute personally to their solution" ([42], p. 482). Environmentalists and scholars suggest gauging environmental concern as an important step toward understanding environmental activism in the nation [21]. The literature indicates that environmental concern is a significant driver of eco-friendly tourist behavior [8], which possibly impact tourists decision-making choices [43]. There is, therefore, a high likelihood that tourists with a high concern for the environment will exhibit eco-friendly tourist behavior [23]. According to this study, tourists with optimistic views have a high level of environmental concern, which, in turn, motivates them to exhibit environmentally friendly behavior such as avoiding throwing garbage into the sea. Therefore, it is hypothesized that environmental concern might moderate the association between optimism (dispositional and explanatory) and eco-friendly tourist behavior.

Hypothesis $\mathbf{3 a}, \mathbf{b}(\mathbf{H} 3 \mathbf{a}, \mathbf{b})$. Environmental concern significantly moderates the relationship of eco-friendly tourist behavior with (a) dispositional optimism and (b) explanatory optimism.

\subsection{Control Variable}

According to the extant literature on environmentally friendly behavior $[43,44]$, this study considers personal factors such as age, gender, and income as control variables to avoid these factors interfering with the prediction of eco-friendly behaviors. Cheung and To [45] suggested that age and gender significantly influence consumers' choice of environmentally friendly behavior. Similarly, Connell [46] highlighted that the income of consumers significantly influences them in selecting products, such as those belonging to the high income group being more likely to engage in eco-friendly behavior. Hence, following Sadiq et al. [44], our study considers age, gender, and household income as control variables in order to avoid their interference in predicting eco-friendly behavior. The above discussion results in the conceptualization of a research model (see Figure 1). 


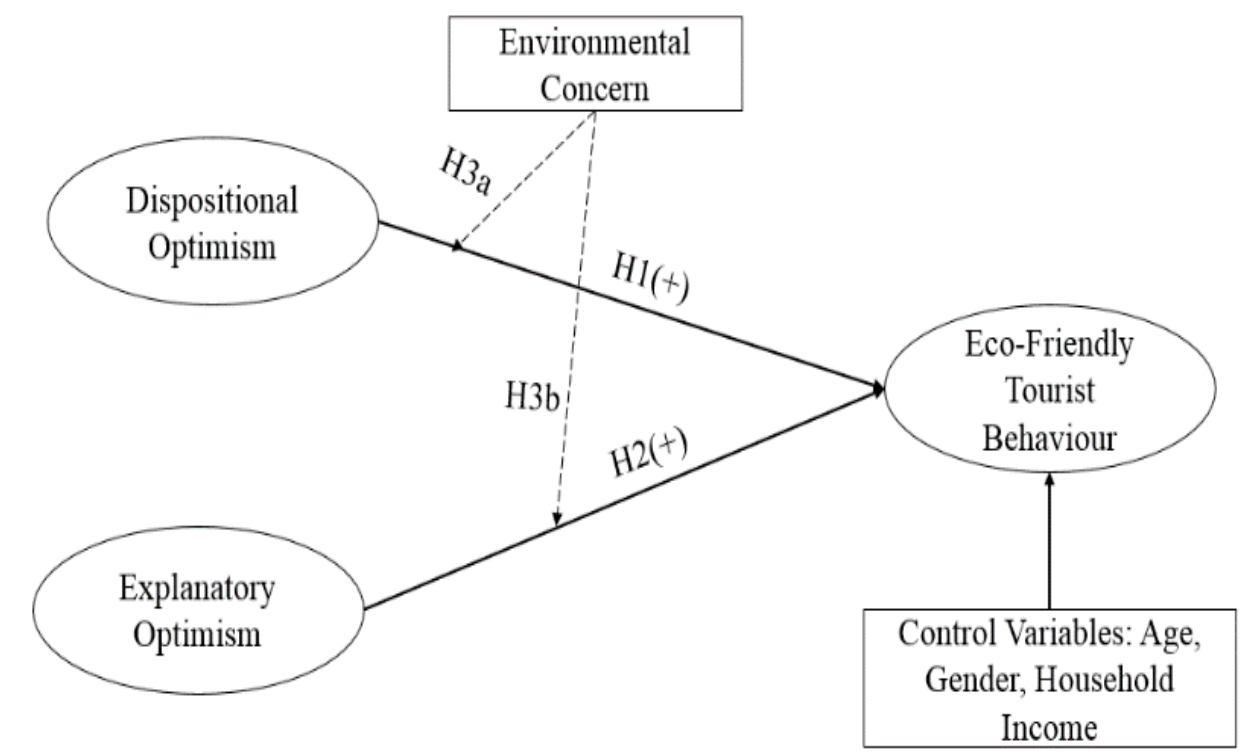

Figure 1. Conceptual model.

\section{Methods}

The present study aims at examining which form of optimism is a better predictor of eco-friendly behavior amongst tourists. The questionnaire consists of 26 items adapted from a number of sources. Dispositional optimism was measured by 6 items drawn from Revised Life Orientation Test scale [47]. The sample items are as follows: "In uncertain time, I usually expect the best" and "I'm always optimistic about my future", among others (see Table 1). Similarly, explanatory style optimism was measured by an 8-item scale adopted from the multidimensional-multiattributional causality (MMC) scale [48]. Following Yuan and Wang [49], we chose achievement and affiliation from the MMC scale, as both are closely linked to daily life activities [50]. The sample items are as follows: "Often chance events can play a large part in causing rifts between friends", "Getting along with people is a skill", among others. Eco-friendly tourist behavior was measured by 8-item of tourist behavior scale of Kvasova [37], and the sample items are as follows: "During my visit to foreign countries as a tourist, I talk with friends about problems related to the environment" and "When I visit foreign countries as a tourist, I avoid buying goods with unnecessary packaging material", among others. Lastly, a 4-item scale was adapted from Sadiq et al. [21] to measure environmental concern. All adapted items were based on a 5-point Likert Scale where 1 and 5 were anchored as "strongly disagree" and "strongly agree", respectively.

Table 1. Measurement items.

\begin{tabular}{lll}
\hline Variable & Item Code & Item \\
\hline \multirow{3}{*}{$\begin{array}{l}\text { Dispositional } \\
\text { Optimism }\end{array}$} & DO1 & In uncertain time, I usually expect the best \\
\cline { 2 - 3 } & DO3 & I'm always optimistic about my future \\
\cline { 2 - 3 } & DO4 & Overall, I expect more good things happen to me than bad \\
\cline { 2 - 3 } & DO5 & I something can go wrong for me, it will \\
\hline DO6 & I rarely count on good things happening to me \\
\hline
\end{tabular}


Table 1. Cont.

\begin{tabular}{|c|c|c|}
\hline Variable & Item Code & Item \\
\hline \multirow{4}{*}{$\begin{array}{l}\text { Environmental } \\
\text { Concern }\end{array}$} & EC1 & The balance of nature is very delicate and can be easily upset \\
\hline & $\mathrm{EC} 2$ & Human beings are severely abusing the environment \\
\hline & EC3 & $\begin{array}{l}\text { Humans must maintain the balance with nature in order } \\
\text { to survive }\end{array}$ \\
\hline & $\mathrm{EC} 4$ & $\begin{array}{l}\text { Human interferences with nature often produce disastrous } \\
\text { consequences }\end{array}$ \\
\hline \multirow{8}{*}{$\begin{array}{l}\text { Eco-friendly } \\
\text { tourist behavior }\end{array}$} & EFTB1 & $\begin{array}{l}\text { During my visit to foreign countries as a tourist, I talk with } \\
\text { friends about problems related to the environment }\end{array}$ \\
\hline & EFTB2 & $\begin{array}{l}\text { During my visit to foreign countries as a tourist, I buy/read } \\
\text { magazines and listen/watch news which focus on } \\
\text { environmental issues }\end{array}$ \\
\hline & EFTB3 & $\begin{array}{l}\text { When I visit foreign countries as a tourist, I avoid } \\
\text { buying goods with unnecessary packaging material }\end{array}$ \\
\hline & EFTB4 & $\begin{array}{l}\text { During my visit to foreign countries as a tourist, I buy } \\
\text { environmentally friendly products, whenever possible }\end{array}$ \\
\hline & EFTB5 & $\begin{array}{l}\text { I reduce and recycle waste, whenever possible, } \\
\text { during my visits to foreign countries as a tourist }\end{array}$ \\
\hline & EFTB6 & $\begin{array}{l}\text { As a tourist, I always like to visit environmentally } \\
\text { friendly countries }\end{array}$ \\
\hline & EFTB7 & $\begin{array}{l}\text { When I visit foreign countries as a tourist, I try to } \\
\text { minimize my consumption of water and energy }\end{array}$ \\
\hline & EFTB8 & $\begin{array}{l}\text { When I visit foreign countries as a tourist, I choose means of } \\
\text { transportation with the least ecological footprint }\end{array}$ \\
\hline \multirow{8}{*}{$\begin{array}{l}\text { Explanatory } \\
\text { Optimism }\end{array}$} & EO1 & $\begin{array}{l}\text { I find that the absence of friendships is often a matter of not } \\
\text { being lucky enough to meet the right people }\end{array}$ \\
\hline & $\mathrm{EO} 2$ & It seems to me that getting along with people is a skill \\
\hline & $\mathrm{EO} 3$ & $\begin{array}{l}\text { I feel that people who are often lonely are lacking in } \\
\text { social competence }\end{array}$ \\
\hline & $\mathrm{EO} 4$ & $\begin{array}{l}\text { In my experience, there is a direct connection between the } \\
\text { absence of friendship and being socially inept }\end{array}$ \\
\hline & EO5 & $\begin{array}{l}\text { I find that the absence of friendships is often a matter of not } \\
\text { being lucky enough to meet the right people }\end{array}$ \\
\hline & EO6 & Difficulties with my friends often start with chance remarks \\
\hline & EO7 & Poor grades inform me that I haven't worked hard enough \\
\hline & EO8 & Sometimes my success on exams depends on some luck \\
\hline
\end{tabular}

To run multivariate analysis techniques such as structural equation modeling, researchers require a sample size of 10 to 15 times of the items considered under the survey to measure relationships amongst the variables [38,51]. Since the current study has 26 items in the questionnaire, therefore, the minimum responses required would be $26^{*} 15=390$. In addition, earlier studies conducted in India by researchers such as Khare [12], Khan, and Kirmani [52] and Sadiq and Adil [53] covered 200-500 participants. Therefore, we approached 400 Indian respondents (who have been on vacation in the last three years) through Amazon Mechanical Turk (MTurk). The survey was administered on 8 August 2021 and ended on 12 August 2021. Of these 400 respondents, 246 (approximately 61.5\%) were male and 154 (approximately 38.5\%) were female (Table 2). The average age (31.6 in years) and average household income (25,001-30,000 INR) of respondents were noted. In spite of the fact that MTurk is becoming increasingly popular among social scientists [54], 
it is not always reliable and, at times, the quality of the data is also contentious $[8,55]$. However, Bentley, Daskalova, and White [56] noted that MTurk helps generate accurate data relatively faster and at a lower cost. Hence, it is evident that researchers can rely on this platform. Furthermore, as a means of overcoming the challenges that MTurk offers, the authors followed the suggestions of Sadiq et al. $[8,20]$ for setting the inclusion criteria. To increase the accuracy rate, we set the following inclusion criteria for the current research. The respondents who were eligible to participate in the survey met the following criteria: (a) completed more than 100 surveys in the past; (b) possess an acceptance rate of $98 \%$ or more.

Table 2. Demographic details.

\begin{tabular}{ccc}
\hline Factor & & Numbers (Frequency) \\
\hline Gender & Male & $246(61.5 \%)$ \\
& Female & $154(38.5 \%)$ \\
\hline Occupation & Student & $83(20.7 \%)$ \\
& Service worker & $271(67.8 \%)$ \\
& Business owner & $37(9.2 \%)$ \\
& Retired & $9(2.3 \%)$ \\
\hline Education & Undergraduate & $318(79.5 \%)$ \\
& Post-graduate & $63(15.75 \%)$ \\
& Ph.D. & $19(4.75 \%)$ \\
\hline
\end{tabular}

\section{Results}

\subsection{Descriptive and Common Method Bias Testing}

Following the suggestions of Khan and Adil [57], this research first tests descriptive analysis followed by multivariate analysis. To check for missing values, this study conducted a frequency test. The result indicates that no missing values are in the data. Furthermore, following Stevens [58], Cook's distance was used to test the outlier. The result indicates that all values were less than 1, which means that there is no outlier. Another reason for data being free from missing values and outliers was the result of sincere checks and monitoring by the researchers during the data collection phase. In addition, in order to test the association between the employed variables-dispositional optimism, explanatory optimism, and eco-friendly tourist behavior (Table 3) —we conducted Pearson's correlation analysis for weak $\left(r=0.145^{* *}\right)$ association between dispositional optimism and explanatory optimism, indicating that both optimisms are similar yet largely different [32]. Previous studies $[59,60]$ also found a weak correlation between the two.

Table 3. Results of descriptive and correlation.

\begin{tabular}{ccccccc}
\hline & Mean & SD $^{\mathbf{1}}$ & DO $^{\mathbf{2}}$ & EO $^{3}$ & EC $^{4}$ & EFTB $^{\mathbf{5}}$ \\
\hline DO & 4.10 & 0.563 & 1 & & & \\
EO & 3.65 & 0.779 & $0.145^{* *}$ & 1 & & \\
EC & 4.18 & 0.704 & $0.438^{* *}$ & $0.294^{* *}$ & 1 & \\
EFTB & 4.09 & 0.570 & $0.522^{* *}$ & $0.187^{* *}$ & $0.237^{* *}$ & 1 \\
\hline Notes $^{1}=$ standard deviation. $^{2}=$ &
\end{tabular}

Notes: ${ }^{1}=$ standard deviation; ${ }^{2}=$ dispositional optimism; ${ }^{3}=$ explanatory optimism; ${ }^{4}=$ environmental concern 5 = eco-friendly tourist behavior; ${ }^{* *} p<0.01$.

Common method bias (CMB) is a major issue in social science research [19]. To assure that our data are free from CMB, we followed two steps: (1) Negatively worded questions were asked to ensure that respondents did not divert from the survey [43]. (2) Harman's single factor test was conducted using exploratory factor analysis (SPSS). The obtained value $(27.3 \%)$ is less than the threshold value (50\%) [61]; therefore, CMB is absent in the collected data. 


\subsection{Hypotheses Testing}

To test the proposed hypotheses, this study used partial least squares structural equation modelling in ADANCO 2.0. Following Dhir, Sadiq, Talwar, Sakashita, and Kaur [62], we adopted a two-step research model test.

First, we test the fitness, reliability, and validity of the research model. Henseler [63] suggests that criteria such as "unweighted least squares discrepancy (dULS)"; "geodesic discrepancy $(\mathrm{dG})$ "; and "standardized root mean square residual (SRMR)" (pp. 22, 23) are required to examine the research model's fitness. The values of dULS, dG, and SRMR should be less than the values at HI99 [63]. The result (see Table 4) indicates that the values of dULS (0.674), dG (0.371), and SRMR (0.048) are less than threshold values. Therefore, the research model exhibits a good model fit.

Table 4. Model fit.

\begin{tabular}{cccc}
\hline & SRMR & dULS & dG \\
\hline Obtained values & 0.048 & 0.674 & 0.371 \\
\hline HI95 & 0.059 & 0.718 & 0.417 \\
\hline HI99 & 0.067 & 0.983 & 0.596 \\
\hline
\end{tabular}

Furthermore, we test the reliability and validity of the research model by assessing McDonald's Omega $(\omega)$, average variance extracted (AVE), Joreskog's rho $(\rho)$, factor loadings ( $\lambda$ ) (see Table 3), and Heterotrait-Monotrait Ratio of Correlation (HTMT) (see Table 4). The results indicate that factor loadings of DO3 (0.48), DO5 (0.39), EO2 (0.57), and EO6 (0.49) are less than the recommended values, i.e., 0.60 [38]. Therefore, these five items were dropped from further analysis. From Table 5, this study interprets the values of $\rho$ that are above the recommended value, i.e., 0.7 ; therefore, the model's reliability is established. Furthermore, the value of each variable's AVE is greater than the recommended value, i.e., 0.50; therefore, convergent validity is established. Table 6 indicates that the values of each variable are less than the threshold, i.e., 0.85 [38]; therefore, discriminant validity is established.

Table 5. Reliability and validity of the model.

\begin{tabular}{|c|c|c|c|c|c|}
\hline Variable & Item Code & $\lambda$ & AVE & $\rho$ & $\omega$ \\
\hline \multirow{4}{*}{ Dispositional Optimism } & DO1 & 0.72 & \multirow{4}{*}{0.61} & \multirow{4}{*}{0.86} & \multirow{4}{*}{0.85} \\
\hline & $\mathrm{DO} 2$ & 0.77 & & & \\
\hline & DO4 & 0.84 & & & \\
\hline & DO6 & 0.79 & & & \\
\hline \multirow{6}{*}{ Explanatory Optimism } & EO1 & 0.75 & \multirow{6}{*}{0.57} & \multirow{6}{*}{0.96} & \multirow{6}{*}{0.82} \\
\hline & EO3 & 0.72 & & & \\
\hline & EO4 & 0.81 & & & \\
\hline & EO5 & 0.77 & & & \\
\hline & EO7 & 0.78 & & & \\
\hline & EO8 & 0.71 & & & \\
\hline \multirow{8}{*}{$\begin{array}{c}\text { Eco-Friendly Tourist } \\
\text { Behavior }\end{array}$} & EFTB1 & 0.77 & \multirow{8}{*}{0.66} & \multirow{8}{*}{0.93} & \multirow{8}{*}{0.87} \\
\hline & EFTB2 & 0.77 & & & \\
\hline & EFTB3 & 0.89 & & & \\
\hline & EFTB4 & 0.85 & & & \\
\hline & EFTB5 & 0.77 & & & \\
\hline & EFTB6 & 0.83 & & & \\
\hline & EFTB7 & 0.85 & & & \\
\hline & EFTB8 & 0.74 & & & \\
\hline
\end{tabular}

Key: $\lambda$ = factor loadings; AVE = average variance extracted; $\rho=$ Joreskog's rho; $\omega=$ McDonald's omega. 
Table 6. HTMT analysis.

\begin{tabular}{cccc}
\hline Construct & DO $^{\mathbf{1}}$ & EO $^{\mathbf{2}}$ & EFTB $^{\mathbf{3}}$ \\
\hline DO & 1 & & \\
\hline EO & 0.15 & 1 & 1 \\
\hline EFTB & 0.58 & 0.18 & \\
\hline
\end{tabular}

Key: ${ }^{1}=$ dispositional optimism; ${ }^{2}=$ explanatory optimism; ${ }^{3}=$ eco-friendly tourist behavior.

In addition, to test the significance of the proposed hypotheses, we examine the $p$ value along with the beta value (see Table 7). It was found that dispositional optimism was positively associated with eco-friendly tourist behavior $(\beta=0.622, p<0.001)$, therefore supporting hypothesis H1. Similarly, the influence of explanatory optimism on eco-friendly tourist behavior was found to be significant $(\beta=0.114, p<0.05)$. Hence, $\mathrm{H} 2$ was also supported. Furthermore, the effect of control variables (Age: $\beta=0.04, p>0.05$; Gender: $\beta=0.07, p>0.05$; Household income: $\beta=0.01, p>0.05$ ) on eco-friendly tourist behavior was insignificant. Lastly, the variance explained in eco-friendly tourist behavior was also found to be $53.7 \%$.

Table 7. Hypotheses testing.

\begin{tabular}{crc}
\hline Relationship & $\boldsymbol{\beta}$ & $\mathbf{f}^{\mathbf{2}}$ \\
\hline$(\mathrm{H} 1) \mathrm{DO} \rightarrow$ Eco-Friendly Tourist Behavior & $0.622^{* * *}$ & 0.372 \\
$(\mathrm{H} 2) \mathrm{EO} \rightarrow$ Eco-Friendly Tourist Behavior & $0.19^{* *}$ & 0.127 \\
\hline $\mathrm{Key}^{* *}=p<0.05^{* * *}=p<0.001$
\end{tabular}

The Cohen $\mathrm{f}^{2}$ value was also calculated to determine the strength of the relationship between dependent and independent variables. The association between dispositional optimism and eco-friendly tourist behavior was strong, as the $\mathrm{f}^{2}(0.372)$ value was above the suggested value (0.35). Similarly, the relationship between explanatory optimism and eco-friendly tourist behavior $\mathrm{f}^{2}(0.127)$ was weak.

\subsection{Moderation Analysis}

To test the moderation effect of environmental concern, this study adopted Model 1 of Process Macro. The results in Table 8 indicate that environmental concern significantly moderates the relationship between dispositional optimism and eco-friendly tourist behavior (see Figure 2). Similarly, it also explains that when environmental concerns are high, explanatory optimism is translated into eco-friendly tourist behavior (see Figure 3). Therefore, H3a and $\mathrm{H} 3 \mathrm{~b}$ are supported.

Table 8. Moderation analysis.

\begin{tabular}{cccccccc}
\hline \multicolumn{7}{c}{ Environmental Concern } \\
\hline & & $\boldsymbol{\beta}$ & $\mathbf{T}$ & $\mathbf{P}$ & LLCI & ULCI & Moderation? \\
\hline $\mathrm{H} 3 \mathrm{a}$ & $\mathrm{DO} \rightarrow$ EFTB & 0.15 & 3.84 & 0.002 & 0.079 & 0.186 & Yes \\
\hline $\mathrm{H} 3 \mathrm{~b}$ & $\mathrm{EO} \rightarrow$ EFTB & 0.11 & 2.97 & 0.038 & 0.041 & 0.135 & Yes
\end{tabular}

Key: $\mathrm{DO}=$ dispositional optimism; $\mathrm{EO}=$ explanatory optimism; EFTB = eco-friendly tourist behavior LLCI = lower level of confidence interval; ULCI = upper level of confidence interval. 


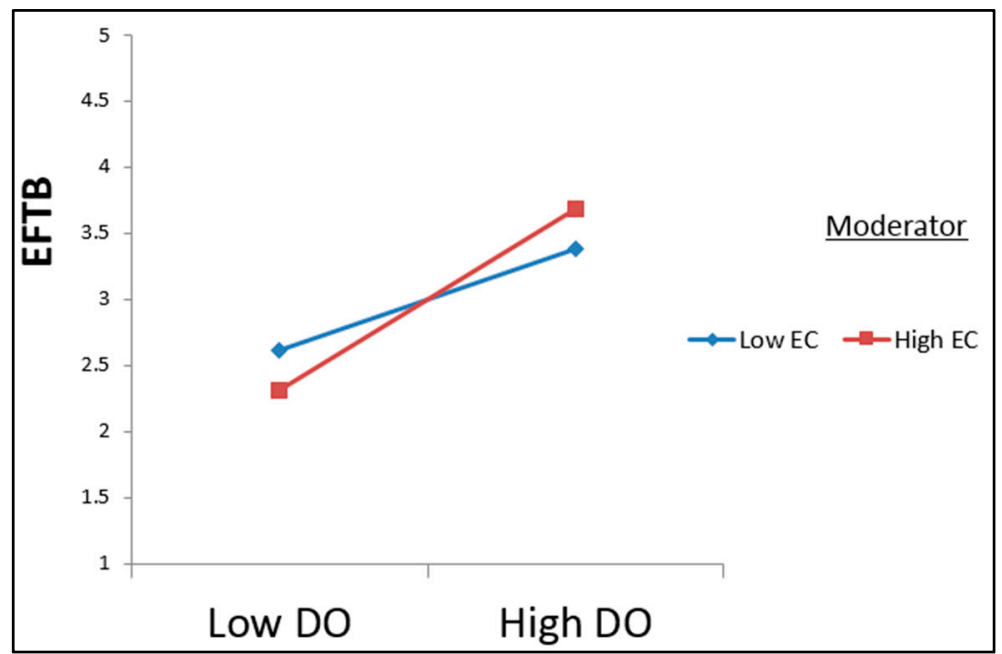

Figure 2. Interaction effect of EC on the link DO and EFTB.

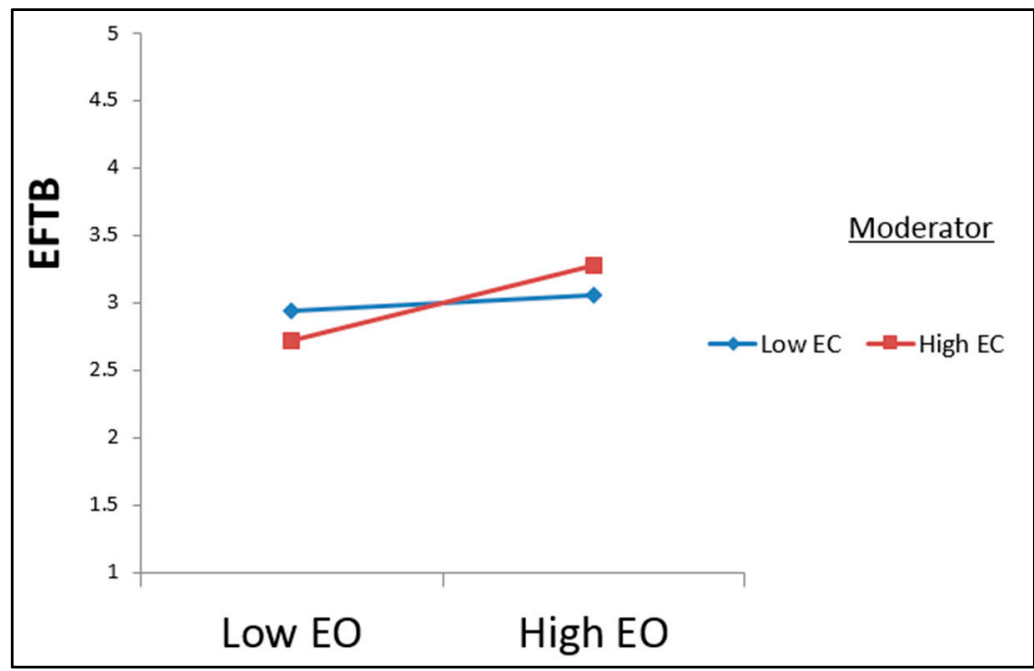

Figure 3. Interaction effect of EC on the link EO and EFTB.

\section{Discussion}

The purpose of our study was to fulfill two research objectives: (a) to explain how tourists make eco-friendly decisions based on dispositional and explanatory optimism; (b) to produce a research model that explains how environmental concerns moderate links between the attributional style of optimism and eco-friendly tourist behavior. Hence, in this section, we discuss the findings of the four tested hypotheses ( $\mathrm{H} 1, \mathrm{H} 2, \mathrm{H} 3 \mathrm{a}$, and $\mathrm{H} 3 \mathrm{~b})$.

The current study aimed to determine which form of optimism is a better predictor of eco-friendly tourist behavior. Since there is a paucity of literature on the subject, this study may provide a guide towards determining which optimism is a better predictor of ecofriendly tourist behavior. Based on the literature, we used dispositional and explanatory optimism as predictors of eco-friendly tourist behavior. Using primary data collected from 400 respondents in India, first, we tested the influence of dispositional optimism on eco-friendly tourist behavior (H1). The study's result illustrates that dispositional optimism significantly influences eco-friendly tourist behavior, implying that it acts as an important guiding force for tourists. Hence, this is in line with the findings of Kaida and Kaida [18] and Sadiq [19], wherein the researchers observed a strong influence of dispositional optimism on pro-environmental behavior. The findings show that tourists who are high on dispositional optimism are more likely to exhibit eco-friendly behavior due to their improved coping skills [40]. Under challenging/risky conditions [20,21], they are less likely to be stressed, and they tend to enjoy life more [64]. One of the plausible interpretations of the result could 
be that dispositional optimist uses adaptive coping strategies, e.g., for acknowledging and trying to change uncontrollable situations, facing challenges directly, persevering during adversity, and attempting to overcome obstacles. Furthermore, tourists with an optimistic tendency tend to be more pro-environmental because they can focus on a positive future [20]. For instance, exhibiting eco-friendly behavior is considered as a costly affair, which at times discourage tourists from participating in pro-environment activities. As a result, tourists needed coping strategies to deal with the additional financial burden. In the same vein, Sadiq et al. [8] suggests that booking eco-friendly hotels may involve financial burden because of greenwashing practices, which affect consumer's trust and future behavior. Furthermore, drawing support from Sadiq [20], it is likely that H1 findings are due to the fact that consumer dispositional optimism is generally regarded as one of the best coping strategies that enables consumers to develop risk-taking capabilities and pro-social behaviors.

In the same manner, $\mathrm{H} 2$ examined the influence of explanatory optimism on ecofriendly tourist behavior. Findings indicate that explanatory optimism is a predictor of eco-friendly behavior; however, it has a weak association. The present study is the first to examine the influence of explanatory optimism in tourism contexts. As such, we assume that respondents might have had negative experiences in their past, which are affecting their future course of actions. For instance, visitors experiencing bad service at green hotel property (negative experience) would show resistance towards pro-environment behavior. Accordingly, Sadiq [19] argued that people who tend to be high on explanatory optimism do not always engage in pro-environmental behavior. Similar observations were also made by Sandra et al. [65], where they found that "not all tourists show pro-environmental behavior". Therefore, based on the empirical results in the current study, we can argue that dispositional optimism is a better predictor of eco-friendly behavior of tourists than explanatory optimism. This concurs with the findings of Scheier and Carver [27] where they found that dispositional optimism is a better predictor of behavior as it does not carry the past negative experiences of an individual and influences his/her decisions.

In order to examine the moderating role of environmental concern, this study tested two hypotheses $(\mathrm{H} 3 \mathrm{a}, \mathrm{b})$. First, this research supports $\mathrm{H} 3 \mathrm{a}$, which states that influences of dispositional optimism on eco-friendly tourist behavior would increase in the presence of high environmental concern. This finding is in line with Sadiq et al. [22], wherein authors discuss the importance of environmental concerns in motivating consumers to adopt ecofriendly behavior. As a possible explanation for this finding, optimistic visitors tend to focus on positive things such as improving the quality of the environment, which can be mitigated through the efforts of individuals as well as society, but sometimes there is hesitation, which can be addressed by introducing the concept of environmental concern to further motivate them to exhibit eco-friendly behavior. Furthermore, this study also supports $\mathrm{H} 3 \mathrm{~b}$, which states that explanatory optimism has a significant influence on eco-friendly tourism when tourist's environmental concern is high. To the best of our knowledge, no study has been grounded on explanatory optimism in eco-friendly consumer behavior; hence, this study shows that tourists have good or bad experiences with respect to saving the environment, such as booking eco-friendly hotels, which is likely to influence their future eco-friendly behavior. As a result, tourists who are concerned with the environment are more likely to engage in eco-friendly behavior at the destination.

\subsection{Implications}

By conducting this study, we made three key contributions to the existing body of knowledge. Firstly, we proposed better predictors (explanatory or dispositional optimism) of eco-friendly tourist behavior. There are only a few studies in the literature that use both types of optimism (see $[32,33,59,60]$ ), but no study has employed both types of optimism in the literature related to pro-environmental behavior. Secondly, in response to the calls of previous scholars such as Kaida and Kaida [18] and Sadiq [19] to examine the complex relationship between dispositional optimism, explanatory optimism, and eco-friendly 
behavior, this study is a first step towards this examination. Third, it is also one of the first studies to examine environmental concern as a moderator between personality traits and actual behavior.

This study's findings will assist marketers' / hotel managers' understanding of how explanatory and dispositional optimism influence and shape tourists' eco-friendly behaviors. Furthermore, hotel management can draft marketing strategies by considering two different types of optimisms as both are very important psychological factors. Hotel management can use promotional strategies that have a psychological effect on tourist's mind, for instance, booking an eco-friendly hotel would have a positive effect on climate. By doing so, hotel management can increase its footfall and also mitigate negative impacts on the climate. Furthermore, the inclusion of environmental concern illustrates how different segments of optimistic tourists behave in the given context. Study findings indicate that enhancing the concern for the environment among optimistic travellers results in the adoption of eco-friendly behaviors at the destination. Therefore, destination management can design marketing strategies that will show that by visiting eco-friendly destination, visitors will help the environment. Additionally, travel planners, practitioners, and hotel managers should be cautious when promoting their properties as eco-friendly. People with explanatory optimism are more likely to carry negative experiences from the past, which in turn largely determines their future environmental behavior. To promote eco-friendly tourist behavior through explanatory and dispositional optimism, management should provide accurate information to tourists and not use unethical practices. This will foster trust and confidence among tourists, allowing them to engage in eco-friendly behavior.

\subsection{Limitations and Future Research Directions}

Similar to any other studies, this one has some limitations. First of all, since the study was conducted in a developing nation, its findings cannot be generalized to developed nations due to cultural differences [19]; therefore, researchers are encouraged to test the current research model in developed nation contexts in future. Secondly, self-reported data can lead to the common method bias [61]; hence, future researchers should be cautious about issues related to the common method bias. Thirdly, the study has not accounted for factors such as socioeconomic background, religion, region, mode of transportation, duration of stay at a destination, etc., into the model that might affect tourists' optimism and pessimism. Fourth, in the present study, demographic variables were not considered as moderating factors on the link between optimism(s) and eco-friendly tourist behavior. Researchers should, therefore, extend the current model by including demographic variables in order to gain a better understanding of tourists' pro-environmental behavior.

Author Contributions: Conceptualization, F.R., S.K.C. and M.A.; methodology, F.R. and M.A.; software, M.A.; validation, S.K.C. and M.A.; formal analysis, M.A.; investigation, F.R. and S.K.C.; resources, F.R. and S.K.C.; data curation, M.A.; writing-F.R., S.K.C. and M.A.; review and editing-F.R. and S.K.C.; visualization, S.K.C.; supervision, F.R.; project administration, F.R., S.K.C. and M.A.; funding acquisition, F.R. All authors have read and agreed to the published version of the manuscript.

Funding: This research received no external funding.

Institutional Review Board Statement: Not applicable.

Informed Consent Statement: Not applicable.

Data Availability Statement: The datasets analyzed during the current study are available on request from the corresponding author. The data are not publicly available due to confidentiality and privacy issues.

Conflicts of Interest: The authors declare no conflict of interest. 


\section{References}

1. United Nations World Tourism Organization (UNWTO). United Nations world tourism organization study on online guest reviews and hotel classification systems: An integrated approach. Serv. Sci. 2016, 8, 139-151. [CrossRef]

2. Juvan, E.; Dolnicar, S. The attitude-behaviour gap in sustainable tourism. Ann. Tour. Res. 2014, 48, 76-95. [CrossRef]

3. Joshi, Y.; Rahman, Z. Factors affecting green purchase behaviour and future research directions. Int. Strateg. Manag. Rev. 2015, 3, 128-143. [CrossRef]

4. Ethical Consumer Research Association. Ethical Consumer Markets Report. Manchester: Author. Available online: http: //www.ethicalconsumer.org/portals/0/downloads/ethical_consumer_markets_report_2014.pdf (accessed on 14 January 2022).

5. Ganglmair-Wooliscroft, A.; Wooliscroft, B. Diffusion of innovation: The case of ethical tourism behavior. J. Bus. Res. 2016, 69, 2711-2720. [CrossRef]

6. Cohen, E. The philosophical, ethical and theological groundings of tourism-an exploratory inquiry. J. Ecotourism 2018, 17, 359-382. [CrossRef]

7. Power, S.; Di Domenico, M.; Miller, G. Risk types and coping mechanisms for ethical tourism entrepreneurs: A new conceptual framework. J. Travel Res. 2020, 59, 1091-1104. [CrossRef]

8. Sadiq, M.; Adil, M.; Paul, J. Eco-friendly hotel stay and environmental attitude: A value-attitude-behaviour perspective. Int. J. Hosp. Manag. 2022, 100, 103094. [CrossRef]

9. Biel, A.; Thøgersen, J. Activation of social norms in social dilemmas: A review of the evidence and reflections on the implications for environmental behaviour. J. Econ. Psychol. 2007, 28, 93-112. [CrossRef]

10. Dolnicar, S.; Grün, B. Environmentally friendly behavior: Can heterogeneity among individuals and contexts/environments be harvested for improved sustainable management? Environ. Behav. 2009, 41, 693-714. [CrossRef]

11. Dolnicar, S.; Leisch, F. An investigation of tourists' patterns of obligation to protect the environment. J. Travel Res. 2008, 46, 381-391. [CrossRef]

12. Khare, A. Antecedents to green buying behaviour: A study on consumers in an emerging economy. Mark. Intell. Plan. 2015, 33, 309-329. [CrossRef]

13. Steg, L.; Vlek, C. Encouraging pro-environmental behaviour: An integrative review and research agenda. J. Environ. Psychol. 2009, 29, 309-317. [CrossRef]

14. Yadav, R.; Pathak, G.S. Determinants of consumers' green purchase behavior in a developing nation: Applying and extending the theory of planned behavior. Ecol. Econ. 2017, 134, 114-122. [CrossRef]

15. Dolnicar, S. Identifying tourists with smaller environmental footprints. J. Sustain. Tour. 2010, 18, 717-734. [CrossRef]

16. Khanra, S.; Dhir, A.; Kaur, P.; Mäntymäki, M. Bibliometric analysis and literature review of ecotourism: Toward sustainable development. Tour. Manag. Perspect. 2021, 37, 100777. [CrossRef]

17. Li, T.T.; Liu, F.; Soutar, G.N. Experiences, post-trip destination image, satisfaction and loyalty: A study in an ecotourism context. J. Destin. Mark. Manag. 2021, 19, 100547. [CrossRef]

18. Kaida, K.; Kaida, N. Wake up for the environment: An association between sleepiness and pro-environmental behavior. Personal. Individ. Differ. 2017, 104, 12-17. [CrossRef]

19. Sadiq, M. Impact of Consumer Optimism and Consumer Pessimism on the Adoption of Pro-Environmental Consumption Behaviour. Master's Dissertation, University of Otago, Dunedin, New Zealand, 2019.

20. Sadiq, M.; Bharti, K.; Adil, M.; Singh, R. Why do consumers buy green apparel? The role of dispositional traits, environmental orientation, environmental knowledge, and monetary incentive. J. Retail. Consum. Serv. 2021, 62, 102643. [CrossRef]

21. Sadiq, M.; Adil, M.; Paul, J. Does social influence turn pessimistic consumers green? Bus. Strategy Environ. 2021, 30, 2937-2950. [CrossRef]

22. Sadiq, M.; Paul, J.; Bharti, K. Dispositional traits and organic food consumption. J. Clean. Prod. 2020, 266, 121961. [CrossRef]

23. Amatulli, C.; De Angelis, M.; Stoppani, A. The appeal of sustainability in luxury hospitality: An investigation on the role of perceived integrity. Tour. Manag. 2021, 83, 104228. [CrossRef]

24. Kim, S.H.; Kim, M.; Han, H.S.; Holland, S. The determinants of hospitality employees' pro-environmental behaviors: The moderating role of generational differences. Int. J. Hosp. Manag. 2016, 52, 56-67. [CrossRef]

25. Verma, V.K.; Chandra, B.; Kumar, S. Values and ascribed responsibility to predict consumers' attitude and concern towards green hotel visit intention. J. Bus. Res. 2019, 96, 206-216. [CrossRef]

26. Peterson, C.; Seligman, M.E. Causal explanations as a risk factor for depression: Theory and evidence. Psychol. Rev. 1984, $91,347$. [CrossRef] [PubMed]

27. Scheier, M.F.; Carver, C.S. Optimism, coping and health: Assessment and implications of generalized outcome expectancies. Health Psychol. 1985, 4, 219-247. [CrossRef] [PubMed]

28. Maier, S.F.; Seligman, M.E. Learned helplessness: Theory and evidence. J. Exp. Psychol. 1976, 105, 3. [CrossRef]

29. Seligman, M.E.; Abramson, L.Y.; Semmel, A.; Von Baeyer, C. Depressive attributional style. J. Abnorm. Psychol. 1979, 88, 242. [CrossRef]

30. Carver, C.S.; Scheier, M.F. Control theory: A useful conceptual framework for personality-social, clinical, and health psychology. Psychol. Bull. 1982, 92, 111. [CrossRef]

31. Diefendorff, J.M.; Gosserand, R.H. Understanding the emotional labor process: A control theory perspective. J. Organ. Behav. Int. J. Ind. Occup. Organ. Psychol. Behav. 2003, 24, 945-959. [CrossRef] 
32. Tomakowsky, J.; Lumley, M.A.; Markowitz, N.; Frank, C. Optimistic explanatory style and dispositional optimism in HIV-infected men. J. Psychosom. Res. 2001, 51, 577-587. [CrossRef]

33. Zhang, J.; Miao, D.; Sun, Y.; Xiao, R.; Ren, L.; Xiao, W.; Peng, J. The impacts of attributional styles and dispositional optimism on subject well-being: A structural equation modelling analysis. Soc. Indic. Res. 2014, 119, 757-769. [CrossRef]

34. Gössling, S.; Bredberg, M.; Randow, A.; Sandström, E.; Svensson, P. Tourist perceptions of climate change: A study of international tourists in Zanzibar. Curr. Issues Tour. 2006, 9, 419-435. [CrossRef]

35. Shamdub, H.; Lebel, L. Identifying tourists with sustainable behaviour: A study of international tourists to Thailand. J. Environ. Manag. Tour. 2012, 3, 26-40.

36. Eslaminosratabadi, H. An investigation on green attitudes and demographics: Understanding the intention of international tourists in Malaysia to pay a premium for green hotels. Eur. J. Tour. Res. 2014, 7, 92-108. [CrossRef]

37. Kvasova, O. The Big Five personality traits as antecedents of eco-friendly tourist behavior. Personal. Individ. Differ. 2015, 83, 111-116. [CrossRef]

38. Hair, J.F.; Sarstedt, M.; Ringle, C.M.; Mena, J.A. An assessment of the use of partial least squares structural equation modeling in marketing research. J. Acad. Mark. Sci. 2012, 40, 414-433. [CrossRef]

39. Taber, J.M.; Klein, W.M.; Ferrer, R.A.; Kent, E.E.; Harris, P.R. Optimism and spontaneous self-affirmation are associated with lower likelihood of cognitive impairment and greater positive affect among cancer survivors. Ann. Behav. Med. 2016, 50, 198-209. [CrossRef] [PubMed]

40. Scheier, M.F.; Carver, C.S. Dispositional optimism and physical health: A long look back, a quick look forward. Am. Psychol. 2018, 73, 1082. [CrossRef]

41. Coelho, F.; Pereira, M.C.; Cruz, L.; Simões, P.; Barata, E. Affect and the adoption of pro-environmental behaviour: A structural model. J. Environ. Psychol. 2017, 54, 127-138. [CrossRef]

42. Dunlap, R.E.; Jones, R.E. Environmental Concern: Conceptual and Measurement Issues. In Handbook of Environmental Sociology; Dunlap, R.E., Michelson, W., Eds.; Greenwood Press: Westport, CT, USA, 2002; pp. 482-524.

43. Dhir, A.; Talwar, S.; Sadiq, M.; Sakashita, M.; Kaur, P. Green apparel buying behaviour: A Stimulus-Organism-BehaviourConsequence (SOBC) perspective on sustainability-oriented consumption in Japan. Bus. Strategy Environ. 2021, 30, $3589-3605$. [CrossRef]

44. Sadiq, M.; Adil, M.; Paul, J. An innovation resistance theory perspective on purchase of eco-friendly cosmetics. J. Retail. Consum. Serv. 2021, 59, 102369. [CrossRef]

45. Cheung, M.F.; To, W.M. An extended model of value-attitude-behavior to explain Chinese consumers' green purchase behavior. J. Retail. Consum. Serv. 2019, 50, 145-153. [CrossRef]

46. Connell, J. Contemporary medical tourism: Conceptualisation, culture and commodification. Tour. Manag. 2013, 34, 1-13. [CrossRef]

47. Scheier, M.F.; Carver, C.S.; Bridges, M.W. Distinguishing optimism from neuroticism (and trait anxiety, self-mastery, and self-esteem): A reevaluation of the Life Orientation Test. J. Personal. Soc. Psychol. 1994, 67, 1063. [CrossRef]

48. Lefcourt, H.M.; von Baeyer, C.L.; Ware, E.E.; Cox, D.J. The multidimensional-multiattributional causality scale: The development of a goal specific locus of control scale. Can. J. Behav. Sci. 1979, 11, 286. [CrossRef]

49. Yuan, W.; Wang, L. Optimism and attributional style impact on the relationship between general insecurity and mental health. Personal. Individ. Differ. 2016, 101, 312-317. [CrossRef]

50. Ngunu, S.; Kinai, T.; Ndambuki, P.; Mwaura, P. Causal attributions as correlates of secondary school students' academic achievement. Educ. Res. Int. 2019, 2019, 1950753. [CrossRef]

51. Hair Jr, J.F.; Sarstedt, M.; Hopkins, L.; Kuppelwieser, V.G. Partial least squares structural equation modeling (PLS-SEM): An emerging tool in business research. Eur. Bus. Rev. 2014, 26, 106-121. [CrossRef]

52. Khan, M.N.; Kirmani, M.D. Role of religiosity in purchase of green products by Muslim students: Empirical evidences from India. J. Islamic Mark. 2018, 9, 504-526. [CrossRef]

53. Sadiq, M.; Adil, M. Ecotourism related search for information over the internet: A technology acceptance model perspective. J. Ecotourism 2021, 20, 70-88. [CrossRef]

54. Kock, N. Common method bias in PLS-SEM: A full collinearity assessment approach. Int. J. E-Collab. 2015, 11, 10. [CrossRef]

55. Ross, J.; Zaldivar, A.; Irani, L.; Tomlinson, B. Who Are the Turkers? Worker Demographics in Amazon Mechanical Turk. Social Code Report. 2009-01. Available online: https:/ / soundideas.pugetsound.edu/faculty_pubs/1013/ (accessed on 7 January 2022).

56. Bentley, F.R.; Daskalova, N.; White, B. Comparing the Reliability of Amazon Mechanical Turk and Survey Monkey to Traditional Market Research Surveys ACM. In Proceedings of the 2017 CHI Conference Extended Abstracts on Human Factors in Computing Systems, Denver, CO, USA, 6 May 2017. [CrossRef]

57. Khan, M.N.; Adil, M. Data analysis techniques in service quality literature: Essentials and advances. Serb. J. Manag. 2013, 8, 95-112.

58. Stevens, J.P. Applied Multivariate Statistics for the Social Sciences; Routledge: London, UK, 2012.

59. Hjelle, L.A.; Busch, E.A.; Warren, J.E. Explanatory style, dispositional optimism, and reported parental behavior. J. Genet. Psychol. 1996, 157, 489-499. [CrossRef] [PubMed]

60. Hull, J.G.; Mendolia, M. Modeling the relations of attributional style, expectancies, and depression. J. Personal. Soc. Psychol. 1991, 61, 85. [CrossRef] 
61. Podsakoff, P.M.; MacKenzie, S.B.; Podsakoff, N.P. Sources of method bias in social science research and recommendations on how to control it. Annu. Rev. Psychol. 2012, 63, 539-569. [CrossRef]

62. Dhir, A.; Sadiq, M.; Talwar, S.; Sakashita, M.; Kaur, P. Why do retail consumers buy green apparel? A knowledge-attitudebehaviour-context perspective. J. Retail. Consum. Serv. 2021, 59, 102398. [CrossRef]

63. Henseler, J. User Manual Adanco 2.0.1; Composite Modeling GmbH \& Co.: Kleve, Germany, 2017; pp. 1-47.

64. Arrosa, M.L.; Gandelman, N. Happiness decomposition: Female optimism. J. Happiness Stud. 2016, 17, 731-756. [CrossRef]

65. Sandra, M.C.L.; João, G.; Heesup, H. Past, present, and future of pro-environmental behavior in tourism and hospitality: A text-mining approach. J. Sustain. Tour. 2021, 30, 258-278. [CrossRef] 